\title{
FOLKLORE VAN SURINAME
}

\author{
EEN BELANGRIJK BOEK
}

DOOR

DR. J. P. B. DE JOSSELIN DE JONG

Melville J. Herskovits and Frances S. Herskovits, Suriname Folk-Lore. With transcriptions of Suriname Songs and musicological analysis by Dr. M. Kolinski (Columbia University Contributions to Anthropology, Volume XXVII), New York, Columbia University Press, 1936.

Dit boek berust op onderzoekingen gedurende de zomers van 1928 en 1929 onder de binnen- en benedenlandsche bevolkingsgroepen van Afrikaansche afkomst in Suriname. De eerstbedoelde groep, die der Boschnegers, is vertegenwoordigd door een aantal spreekwoorden, raadsels en gezangen in het Saramacca-dialect en meer dan 100 Djoeka-liederen, terwijl de musicologische beschrijving (door Dr. M. Kolinski) op beide groepen betrekking heeft. Verreweg het grootste deel van het boek is echter gewijd aan de benedenlandsche en speciaal aan de negerbevolking van Paramaribo. Reeds in een vroegere voorloopige publicatie over de sociale organisatie der Boschnegers (in Proceedings of the twentythird international congress of americanists, New York 1930, p. 713) en in hun aardig boek Rebel Destiny, Among the Bush-Negroes of Dutch Guiana (New York 1934) hadden de auteurs getoond, met veel profijt onder deze slecht bestudeerde bevolkingsgroep gewerkt te hebben, zoodat de volledige publicatie van hun resultaten met spanning werd tegemoetgezien. Het boek, dat thans voor ons ligt, heeft onze groote verwachtingen niet beschaamd. Onder den bescheiden titel van ,,Suriname Folk-Lore” geeft het niets minder dan een zorgvuldige ethnologische beschrijving van de stadsnegerbevolkig en een aanzienlijk deel der inheemsche litteratuur in Negerengelsch en Engelsche vertaling met taalkundige toelichting en een rijk vergelijkingsmateriaal aan Westafrikaan-

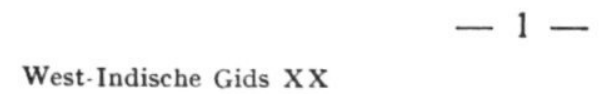


sche en Antillische parallelen. Ongetwijfeld zijn de schrijvers erin geslaagd te bewijzen, wat door sommigen wel eens betwijfeld werd, dat ook de cultuur der gechristianizeerde en gemodernizeerde stadsbevolking nog tal van duidelijk traceerbare Westafrikaansche elementen bevat, en zelfs in 't algemeen nog een onmiskenbaar Westafrikaansch karakter vertoont. De term „Westafrikaansch", hoewel vaag, is in dit geval bruikbaar, omdat ondanks alle taal-en cultuurverschillen tusschen de vele Westafrikaansche volken, die in het Surinaamsche mengelmoes vertegenwoordigd zijn, dat heele Westafrika, vergeleken bij al wat Amerikaansch of Americano-Europeesch is, zich als een betrekkelijk homogeen cultuurgebied aan ons voordoet. Wij kunnen dit gebied trouwens nog wel iets nader omgrerzen, want het wordt steeds duidelijker, dat in alle onder Afrikaanschen invloed tot stand gekomen taal- en cultuurcreolizeerirgen in Amerika het Westsoedaneesche element overheerschend is. Wat de taalcreolizeeringen betreft was daar reeds vroeger op gewezen, zoo o.a. ten aanzien van het Negerhollandsch van St. Thomas en St. John (zie Mededeelingen Koninkl. Akad. v. Wetensch. 57, serie A, No. 4), en dat het ook van de overige cultuur geldt, mag na het grondig onderzoek dat ons nu bezighoudt als bewezen worden beschouwd.

Het spreekt vanzelf, dat ook dit boek van 766 bladzijden tal van speciale kwesties onopgelost laat en dat de beoordeeling der gegevens, bijvoorbeeld in de ethnologische beschrijving, soms voor discussie vatbaar is. De schrijvers zelf wijzen trouwens uitdrukkelijk op het voorloopig karakter van hun zienswijze ten aanzien van allerlei punten waarop na de uitwerking en publicatie van al hun in Westafrika verzamelde gegevens waarschijnlijk nog wel nieuw licht zal vallen. De beschikbare plaatsruimte gedoogt niet op dit alles in te gaan. Wij zullen ons moeten beperken tot een beknopt overzicht van den rijken inhoud en een paar opmerkingen over erkele nieuwe of althans nu voor 't eerst duidelijk beschreven gegevens van bijzonder belang.

De st of is verdeeld over drie afdeelingen. Part I, getiteld ,Notes on the Culture of the Paramaribo Negroes", behandelt het geheel van gebruiken en opvattingen, dat als karakteristiek voor dit deel der bevolking mag gelden. Wij zullen niet alle titels van afzonderlijke paragraphen opsommen, maar alleen vermelden, dat o.a. afzonderlijke schetsen worden gewijd aan ,The Koto-Missi", „Fiofio", ,Gods and Familiar Spirits”, ,Magic, Good and Evil”, „The Spirits of the Dead”. Part II geeft „Stories, Riddles, Proverbs and Dreams". Het materiaal zelf omvat 148 verhalen 
uit Paramaribo, 106 raadsels, voor verreweg 't grootste deel eveneens uit Paramaribo, 144 spreekwoorden in taki-taki of benedenlandsch Negerengelsch, 49 spreekwoorden van de Saramaccagroep en 29 inheemsche droomverklaringen, en wordt voorafgegaan door een zorgvuldige wetenschappelijke inleiding, die rekenschap aflegt van de methode van opneming en de gebruikte spelling en verder als een taalkundige, folkloristische en ethnologische toelichting gekenschetst kan worden. Part III is gewijd aan de muziek.Ook dit deel is in verschillende hoofdstukken verdeeld. Eerst komt de musicologische analyse door Dr. Kolinski; daarop volgen een voorloopige ethnologische beoordeeling en een beschrijving der muziekinstrumenten. Het materiaal bestaat uit 263 liedjes, waarvan 112 van de Djoeka, 143 van de Stads-negers en 8 uit Haiti afkomstig zijn. En eindelijk volgen dan nog eenige analyses van toonstructuur en verscheidene woorden- en andere lijsten als appendices.

Wat de ethnologische inleiding aangaat, zij hier in de eerste plaats de aandacht gevestigd op de interessante mededeelingen en beschouwingen over de hoofddoek en de belangrijke rol die dit kleedingstuk in het leven der Surinaamsche vrouw vervult. De figuurpatronen dezer doeken worden aangeduid met namen die, in den vorm van een spreekwoord of op andere wijze, een toespeling bevatten op een gebeurtenis, een situatie, dikwijls van erotischen aard, die men hekelt. Er bestaat in den regel geen enkel verband tusschen den naam en de versiering waarop hij doelt; in de enkele gevallen dat er wel eenig verband valt te constateeren, wanneer bijv. een doek klaarblijkelijk genoemd is naar de overheerschende kleur der figuren, bevat de naam, zoover de ervaring der auteurs gaat, geen sociale toespeling. Ook de bindwijzen worden aangeduid met namen. In dit geval bestaat er wel verband. Deze namen hebben namelijk vooral betrekking op de stemming van de draagster, en de bindwijzen drukken hetzelfde uit. Zoo geeft de bindwijze genaamd trobi (,,trouble") te kennen, dat de draagster van de doek aan een slecht humeur lijdt en dat men beter doet, uit haar buurt te blijven. Deze bindwijze is gekenmerkt door een driehoekig vouwsel, netjes van voren, maar met loshangende einden van achteren. De auteurs wijzen erop, dat dit namensysteem in verband met de hoofddoek typisch Westafrikaansch is. Wij mogen vermoeden, dat het ontbreken van verband tusschen figuurpatroon en naam een (in betrekkelijken zin) moderne trek is en een gevolg van het ongebreidelde gebruik van bedrukte katoentjes met hun onbegrensde patroonsvariatie. Het 
zou zeker van belang zijn, na te gaan, hoe dit gebruik zich verder ontwikkelt.

Zeer belangrijk zijn ook de mededeelingen over de socio-familiale en de religieuze banden tusschen ouders en kinderen. In sociaal opzicht bestaat er een zeer sterke band tusschen moeder (resp. moeder's familie in de vrouwelijke lijn) en kind. Ofschoon de stadsbevolking, naar de gepubliceerde gegevens te oordeelen, geen clan-systeem meer heeft, blijkt toch wel duicelijk, dat het ook hier vooral gaat om het onderscheid tusschen patrilineale en matrilineale verwantschap. Bepaalde verboden van bovennatuurlijke orde (taboe's), genaamd trefu of kina, zijn erfelijk in de mannelijke lijn. Divinatie-technieken en winti (goden of demonen) worden bij voorkeur nagelaten door een man aan zijn broer en door een vrouw aan haar zuster. Is men de laatste van zijn generatie, dan vererft dit bezit van een vrouw op haar dochter en van een man op zijn zuster's zoon. Ontbreken kinderen, dan denkt een vrouw in de eerste plaats aan haar zuster's dochter en een man aan zijn zuster's zoon. Uitzonderingen op deze regels ontbreken weliswaar niet, maar het valt toch niet te betwijfelen, dat voor beide soorten van bovennatuurlijk bezit matrilineale vererving als normaal wordt beschouwd. Dit geldt ook van kunu, de bovennatuurlijke straf voor het schenden van een taboe in den vorm van de bezoeking door een boosaardigen winti als kwelduivel. Het is de moeite waard eraan te herinneren wat ons sinds de belangrijke, hoewel zeer beknopte, mededeelingen van Dr. Herskovits in zijn bovenvermeld opstel van de Boschnegers dienaangaande bekend is. De schrijver trof daar een duidelijk matrilineaal clan-stelsel aan. De Aucaners kennen heilige clan-dieren, tref genaamd, die dus erfelijk zijn in de vrouwelijke lijn. Bij de Saramacca-groep werd dit geloof niet gevonden, maar hier bleken zekere bovennatuurlijke genees- en afweermiddelen matrilineaal te vererven. Beide groepen kennen bovendien voedsel-taboe's en afweermiddelen, die als patrilineaal erfelijk gelden. De auteurs brengen deze tweeërlei erfelijkheid in verband met het dubbele clansysteem of, zooals zij. het uitdrukken, de ,,dubbele exogamie”, bij Afrikaansche volken als de Ashanti. Inderdaad werpen de Afrikaansche gegevens een helder licht op den achtergrond dezer verschijnselen. Het is nauwelijks aan twijfel onderhevig, dat de voedsel-taboe's overblijfselen zijn van een patrilineaal clantotemisme, terwijl de clan-dier-vereering als het overblijfsel van een matrilineaal totemisme is op te vatten. Dat de clans bij de Boschnegers ook nu nog ,,min of meer" gelocalizeerd zijn, wijst 
op een locaal matrilineaal clan-totemisme. In verband hiermee is het de moeite waard op te merken, dat ook bij de stadsbevolking de belangrijkste groep van winti de ,,aardmoeder"'-groep is, d.w.z. de vrouwelijke godheden van de plaats, het gebied, de aarde, in haar verschillende manifestaties. Tegenover de aarde-groep, die zich vooral in den vorm van slangen openbaart, staat de groep van hemel-godheden, zooals de 7 dondergoden, die zich eveneens als slangen kunnen incarneeren. En daar dit ook van alle soorten van demonische wezens inclusief de voorouders geldt, kan men zeggen, dat alles samenvloeit in de slang. Dit blijkt ook uit de voorstelling, dat de hemelgoden zich vereenigen met vrouwelijke slangen en omgekeerd de aardgodheden met mannelijke slangen. Hemel en aarde zijn in deze voorstelling dus het mannelijke en het vrouwelijke aspect van het alles omvattende en dus natuurlijk ook tweeslachtige slangewezen. De voorouders zijn in het ritueel met de aarde geassocieerd. Het ligt voor de hand te vermoeden, dat deze voorstelling meer in 't bijzonder - vroeger wellicht uitsluitend - de matrilineale voorouders geldt, maar uit de thans beschikbare gegevens valt een mythisch onderscheid tusschen patrilineale en matrilineale voorouders niet met zekerheid af te leiden. Wie zich een denkbeeld wil vormen over de mythische stelsels in Afrika, waarin het Surinaamsche voorstellingscomplex ongetwijfeld wortelt, zij hier, behalve naar de door de schrijvers vermelde litteratuur, ook nog verwezen naar $\mathrm{H}$. G. Luttig, The religious system and social organisation of the Herero. A study in Bantu culture (Utrecht 1934) en over de mythische beteekenis van de slang in tal van culturen raadplege men G. W. Locher, The serpent in Kwakiutl religion. A study in primitive culture (Leiden 1932).

Part II, dat ongeveer de helft van het heele boek in beslag neemt, is niet minder rijk aan gegevens en beschouwingen die tot nadere gedachtewisseling aanleiding geven dan de ethnologische beschrijving bleek te zijn. Wij moeten ons weer tot enkele punten bepalen. Van bijzonder belang is het zeer nauwgezet onderzoek naar de herkomst van een aantal uitdrukkingswijzen, waarvan de schrijvers terecht niet konden aannemen, dat zij eenvoudig als uitingen van onbeholpenheid bij het gebruik der vreemde taal zouden zijn te beschouwen. Hun studie van de gepubliceerde gegevens, aangevuld door eigen onderzoek in Westafrika, heeft hen in staat gesteld de Arikaansche herkomst van het grootste deel dier morphologische en syntactische eigenaardigheden onomstootelijk vast te stellen. De bereikte resultaten wettigen de verwach- 
ting, dat voortgezet onderzoek door specialisten op 't gebied der Westsoedaneesche talenwereld nog heel wat aanrakingspunten aan 't licht zullen brengen, die niet zoo aan de oppervlakte liggen en daardoor tot nog toe aan de aandacht zijn ontsnapt. Waarschijnlijk zal dan ook de overwegend Westsoedaneesche geaardheid van het klanksysteem komen vast te staan. Dat verreweg het grootste deel van den woordenschat al dezer Westindische specimina van taalcreolizeering aan de Europeesche talen waarmee men te maken had (Engelsch, Nederlandsch, Portugeesch, Spaansch) ontleend is, sluit volstrekt niet de mogelijkheid uit, dat de ontwikkeling der klanksystemen niettemin in hoofdzaak door typisch Westsoedaneesche tendenties beheerscht bleef.

$\mathrm{Na}$ het gezegde behoeft het geen betoog, dat het den schrijvers ook niet moeilijk viel, het overwegend Afrikaansche karakter der inheemsche litteratuur in 't licht te stellen .Het is opmerkelijk, dat de bevolking van Paramaribo niet, zooals de overeenkomstige bevolkingsgroep op St. Thomas en St. John, onderscheid maakt tusschen,,oldtime stories" en ",stories from books" of ,,school stories" (zie Het huidige Negerhollandsch, Verh. Kon. Akad. v. Wet. Amsterdam 1926) Alle verhalen noemt men in Paramaribo Anansi-tori en de auteurs verklaren dit uit een Ashanti-mythe, die verhaalt hoe Anansi op deze wijze werd beloond voor zijn werk in dienst van God. Het is mogelijk, dat de auteurs in zooverre gelijk hebben (zij konden zich op een zeer besliste uitlating van den Ashanti-kenner Rattray beroepen), dat de bedoelde mythe inderdaad nog in Suriname heeft doorgewerkt, maar daarmee is nog niet verklaard, dat men zelfs in het doodenritueel geen onderscheid maakt tusschen daarbij hoorende en niet daarbij hoorende vertellingen. Ook op de bovengenoemde eilanden spelen de Anansi-verhalen een rol in het doodenritueel, maar al wat men tot de boeken- of schoolverhalen rekent komt niet in aanmerking om bij die gelegenheid te worden voorgedragen. Weliswaar is de onderscheiding ook hier, historisch beschouwd, vrij willekeurig. Gepubliceerd en ongepubliceerd sprookjes- en mythenmateriaal van beide vastelanden is in de litteraire traditie tot een onontleedbaar geheel vergroeid, zoodat soms bijna woordelijk uitGrimm navertelde sprookjes als ,old-time stories" gelden, terwijl op school en via verzamelingen als „Uncle Remus” in omloop gebrachte Afrikaansche sprookjes niet als zoodanig worden herkend en dus bij ,,school stories" worden ingedeeld. Dit neemt echter niet weg, dat men een traditioneele tegenstelling oud-eigen - 
nieuw-vreemd kent en tracht te handhaven. Wellicht moeten wij de verklaring zoeken in de omstandigheid, dat deze Negerhollandsche taalgemeenschap, tevens de draagster der Negerhollandsche traditie in ruimeren zin, uit een kleine, snel uitstervende groep van ouderen bestaat, die van de jongere geslachten - die de taal zelfs niet kennen - geen steun meer krijgt, maar evenmin — juist tengevolge van haar isolement - voor modernizeerende invloeden van die jongeren vatbaar is. In Paramaribo daarentegen, waar de Negerengelsche traditie en wat daarmee samenhangt gedragen wordt door de gansche Afrikaansche bevolkingsgroep, een integreerend deel der levende cultuur vormt, en dus niet door een kloof van het cultuurleven eener jongere generatie gescheiden is, voltrekt zich een modernizeeringsproces, dat op den duur ook de meest essentieele elementen der oude cultuur aantast - ook zonder dat men bewust met dat oude breekt of het heele complex mèt de oudste generatie van het tooneel verdwijnt.

Dat de verhalenschat ook voor de bevolking zelf tot litteratuur geworden is, men kan wel zeggen tot profane litteratuur, ondanks het nog steeds niet verbroken verband met het doodenceremonieel, blijkt ook uit het ontbreken van echte mythen, onverbreekbaar verbonden met het godsdienstig ritueel, waarvan zij als ' $t$ ware rekenschap geven. Misschien is dit desintegratie-proces bij de Boschnegers nog niet zoo ver gevorderd. Althans bleek de religieuze beteekenis van vele liederen daar nog niet zoozeer vervaagd te zijn als bij de stadsbevolking. Het kostte den schrijvers vaak moeite, den juisten tekst te bemachtigen; de namen van voorouders en andere bovennatuurlijke wezens trachtte men achter te houden en het zingen in de phonograaf werd dikwijls voorafgegaan door een toelichtende verontschuldiging jegens de voorouders. Het zeer ouderwetsch karakter dezer gezangteksten, vooral van die in de geheime Kromanti-taal, valt trouwens niet meer te betwijfelen sedert de schrijvers de merkwaardige ontdekking hebben gedaan, dat hun Fanti- en Ashanti-zegslieden van de Goudkust een aantal dezer liedjes geheel konden vertalen. Van deze Kromanti-litteratuur zijn dus blijkbaar heele stukken nog nagenoeg zuiver Afrikaansch; geen wonder, dat een zoo zorgvuldig bewaarde traditie haar sacralen aard nog niet verloren heeft.

De voltooiïng van dit belangrijke werk, welks rijke inhoud in deze beknopte bespreking niet tot zijn recht kon komen, is een gelukwensch zeker waard. Nu de schrijvers eenmaal hun aan- 
8 J. P. B. DE JOSSELIN DE JONG FOLKLORE VAN SURINAME

dacht op Suriname hebben gericht, mogen wij hopen, dat zij het niet bij dit eerste onderzoek zullen laten, maar zullen voortgaan, zich te wijden aan een wetenschappelijke taak, die Nederland blijkbaar gaarne aan anderen overlaat - maar beschamend is het!

Oegstgeest, October 1937. 